\title{
THE ANAESTHETIC MANAGEMENT OF PRETERM INFANTS UNDERGOING LIGATION OF PATENT DUCTUS ARTERIOSUS
}

\author{
George G. Neuman and Dolly D. Hansen
}

\begin{abstract}
The authors reviewed the records of seventy preterm infants suffering from respiratory distress syndrome and, in most cases, refractory congestive heart failure, who underwent ligation of patent ductus arteriosus. The peri-operative management of these patients is described. The anaesthetic technique consisted of nitrous oxide and oxygen supplemented with a relaxant. All patients were ventilated manually with a humidified Jackson Rees system. The operations were performed in the main operating suite. There were no deaths during operation. The infants were protected from significant temperature fluctuations by various methods which are described. The overall survival rate of all preterm infants with respiratory distress syndrome. The management presented is considered acceptable to the infants, to the surgeons and to the anaesthetists.
\end{abstract}

THE REPORTED INCIDENCE of patent ductus arteriosus in preterm infants weighing less than 2500 grams has more than doubled over the last decade. ${ }^{1}$ The issue of when to ligate the ductus continues to be debated. When the preterm infant with a patent ductus arteriosus develops intractable cardiac failure in combination with varying degrees of respiratory distress syndrome, few would argue against efforts to close the ductus. The closure may take the form of either surgical ligation or pharamacological intervention with a prostagladin synthetase inhibitor such as indomethacin. ${ }^{2}$

Anaesthetists are being called upon more and more frequently to anaesthetize these critically ill infants. The present report deals with the anaesthetic and immediate postoperative management of 70 preterm infants who underwent surgical ligation of patent ductus arteriosus.

\section{Materials AND METHODS}

\section{Patients}

We reviewed the records of 70 preterm infants who underwent surgical ligation of a patent ductus arteriosus during the period from January $I$, 1973 to December 31, 1978, at the Children's Hospital Medical Center in Boston. Table I summarizes the characteristics of the infants reviewed. Thirty of the infants were female and 40

George G. Neuman, M.D., Assistant in Anaesthesia, Dolly D. Hansen, M.D., Assistant in Anaesthesia, The Children's Hospital Medical Center, 300 Longwood Avenue, Boston, MA. 02115 , U.S.A.

Dr. Neuman's current address is: New York University Medical Center, 500 First Avenue, New York, U.S.A.

Canad. Anaesth. Soc. J., vol. 27, no. 3, May 1980 were male. This ratio is consistant with the ratio of female to male births in preterm infants. ${ }^{3}$ The infants were subdivided by weight (Table I) and a striking female predominence was found in infants below 1000 grams. In the group weighing more than 1000 grams there was a strong male predominence.

The gestational age was 29.5 weeks with a range of 24 to 38 weeks. The mean weight at the time of the operation was 1246 grams with a range of 700 to 2700 grams.

The incidence of twins was extremely high (18.6 per cent) when compared to the incidence of twins in the normal population (1.08-1.36 per cent) ${ }^{4}$ There were two sets of identical twins in the group. Three siblings of the remaining nine twins died at birth. No follow up information was available on the other six.

The seasonal variation of the birth dates was examined and no significant trend was found.

The diagnosis of a haemodynamically significant patent ductus arteriosus was made primarily by physical examination. Bounding pulses, a continuous murmur, signs of increasing cardiac failure and apnoeic spells as well as continued respiratory failure were the most commonly encountered signs. In recent years radionucleotide scan and echocardiography have been used to support the diagnosis. Relatively few invasive procedures such as cardiac catheterization or aortic injection were used.

The infants were divided into two groups relative to their respiratory status before operation. Group A included 46 infants with severe respiratory distress syndrome who had tracheal intubation and mechanical pulmonary ventilation from birth (44 patients) or within 72 hours of age (two 
TABLE I

Characteristics of the 70 Patients who Underwent Ligation of Patent Ductus ARteriosus

\begin{tabular}{lccc}
\hline \hline & $<1000$ grams & $1100-1500$ grams & $>1500$ grams \\
\hline Sex & $17 \mathrm{~F}, 7 \mathrm{M}$ & $8 \mathrm{~F}, 23 \mathrm{M}$ & $5 \mathrm{~F}, 10 \mathrm{M}$ \\
Gestational age (weeks) & $27.7 \pm 2.1$ & $29.1 \pm 1.6$ & $33.4 \pm 2.4$ \\
$\begin{array}{l}\text { Age at operation } \\
\text { Weight at operation (g) }\end{array}$ & $127.7 \pm 3.7$ & $16.7 \pm 11.2$ & $13.1 \pm 6.4$ \\
$\begin{array}{l}\text { Days on ventilator before } \\
\text { operation }\end{array}$ & $873 \pm 100$ & $1206 \pm 114$ & $1870 \pm 205$ \\
$\begin{array}{l}\text { Oxygen concentration before } \\
\text { operation (per cent) }\end{array}$ & $10.1 \pm 5.6$ & $10.4 \pm 7.2$ & $10.7 \pm 7.9$ \\
Per cent survival & $31.2 \pm 9.3$ & $36.2 \pm 14.3$ & $35.7 \pm 21.8$ \\
\hline
\end{tabular}

patients). Group B included 19 infants with moderate to mild respiratory distress syndrome who were either intubated after 72 hours of age (11 patients) or did not require tracheal intubation at any time before operation (eight patients). The records of the remaining five patients were incomplete with respect to this information.

During the period before operation more than 90 per cent of the infants were treated with digoxin and 66 per cent required a diuretic, usually furosemide, for cardiac failure.

The mean age at operation was $13.9 \pm 6.1$ days. The mean number of days on a ventilator before operation was $10.3 \pm 6.8$ days. The majority of patients were past the peak of their respiratory distress syndrome and required a mean inspired oxygen concentration of $34.3 \pm 14.3$ per cent to maintain a mean arterial oxygen tension of $8.34 \pm$ $2.46 \mathrm{kPa}(62.8 \pm 18.5 \mathrm{~mm} \mathrm{Hg})$ immediately before operation. The oxygen concentration was maintained in this range to avoid the reported toxic effects of oxygen, such as retrolental fibroplasia.

During the last three years of the study, 11 infants had a trial of indomethacin for closure of patent ductus arteriosus. The drug had to be discontinued due to either a decrease in renal function (seven patients) or the development of a coagulopathy (three patients). These infants subsequently underwent surgical ligation of the ductus.

A number of infants in the study were transferred back to their referring hospital (usually the Boston Hospital for Women) by the third postoperative day and were subsequently lost to follow up ( 15 patients).

\section{METHODS}

All of the infants underwent ligation of the patent ductus arteriosus in the main operating room suite under general anaesthesia. Each infant's temperature was measured with a glass thermometer before leaving the neonatal intensive care unit. The infants were transported to the operating room in a heated isolette. During the first 3-4 years, the isolette in which the baby was nursed in the Intensive Care Unit was taken to the operating suite. During the operation the empty isolette was connected to an electrical outlet and kept warm for the transport back to the neonatal care unit postoperatively. Lately a battery powered transport isolette is being used. The majority of infants had the trachea intubated and were ventilated by the Baby Bird ventilator* in the intensive care unit. An anaesthetist accompanied these patients to the operating room and ventilated them by hand with an air and oxygen mixture using a Jackson Rees system.

Upon arrival at the preheated operating room $\left(80^{\circ} \mathrm{F}\right)$ the infant was placed on a heated water mattress and heating lamps were used until skin preparation with a warm antiseptic solution and the draping were completed. The infants were monitored with a blood pressure cuff and Doppler apparatus, electrocardiograph, oesophagealstethoscope and a rectal or oesophageal thermistor. The majority of infants had either umbilical or radial artery catheters. The arterial pressures were transduced and monitored with Hewlett-Packard $\ddagger$ equipment. The catheter was infused continuously with heparinized saline at a rate of $0.63 \mathrm{ml}$ per hour. If the infant did not have a satisfactory peripheral venous line, a percutaneous 22 gauge teflon catheter was usually placed by the anaesthetist. The aim of the team of anaesthetist and surgeons was to proceed with the preparation and surgery at the maximum safe speed.

*Bird Corporation.

†Hewlett-Packard Co. 
The eight infants in whom the trachea was not previously intubated were pre-oxygenated, given atropine $0.02 \mathrm{mg} \cdot \mathrm{kg}^{-1}$ paralyzed with intramuscular $\left(4.0 \mathrm{mg} \cdot \mathrm{kg}^{-1}\right)$ or intravenous $\left(2.0 \mathrm{mg} \cdot \mathrm{kg}^{-1}\right)$ succinylcholine and a nasotracheal intubation was done. Succinylcholine was not given until it had been proven that ventilation with a face mask could be done with ease. Provided the necessary small equipment is available tracheal intubation of small infants is not in itself more difficult than intubation of full term neonates. A Miller \#0 laryngoscope blade is preferred and if necessary the smallest Magill forceps is used to guide the treacheal tube into the larynx. The infants were ventilated with a heated and humidified mixture of nitrous oxide and oxygen. The inspired oxygen concentration was maintained at a level 10 to 15 per cent higher than the patient required in the intensive care unit. Mean inspired oxygen concentration during operation was $49 \pm 12$ per cent, reflecting the use of a mixture of 50 per cent nitrous oxide and 50 per cent oxygen in most cases. Infants who required minimal ventilatory assistance before operation were given intravenous succinylcholine in divided doses as the relaxant for the procedure. The mean total dose was $7.8 \pm 4.2 \mathrm{mg} \cdot \mathrm{kg}^{-1}$. Infants who were more dependant on the ventilator received either $d$ tubocurarine chloride or pancuronium bromide in total doses of $0.67 \pm 0.31 \mathrm{mg} \cdot \mathrm{kg}^{-1}$ and $0.12 \pm$ $0.07 \mathrm{mg} \cdot \mathrm{kg}^{-1}$ respectively. These drugs were not reversed at the end of the operation. Table II summarizes the anaesthetic agents used. All infants had a left chest tube placed during the operation.

At the end of the operation the infants were transported to the neonatal intensive care unit in a heated isolette. Upon arrival in the unit their vital signs were measured, including temperature, which was taken with the same glass thermometer used previously on that infant.

\section{RESULTS}

The mean anaesthesia and operating times were $66.9 \pm 19.2$ minutes and $34.7 \pm 15.3$ minutes respectively. The difference between the times reflects time spent positioning the infant and applying the necessary monitoring devices. There were no deaths during operation.

A small number of infants required inotropic support during operation. Two needed isoproterenol; one of these was receiving this medication when he arrived in the operating room, the second required it during resuscitation from a massive surgical haemorrhage. Eleven infants required calcium gluconate in a dose of $50 \mathrm{mg} \cdot \mathrm{kg}^{-1}$. Atropine sulfate $0.02 \mathrm{mg} \cdot \mathrm{kg}^{-1}$ was administered to a number of infants for correction of bradycardia which was usually secondary to retraction of the left lung.

Forty-four per cent of the patients received transfusions during operation. The mean volume of transfusion was $16.8 \pm 22.2 \mathrm{ml}$ of whole blood. Two infants required $100 \mathrm{ml}$ and $86 \mathrm{ml}$ of blood respectively due to severe surgical haemorrhage. Sixty-eight per cent of the infants required blood transfusions within the first 12 hours after operation, the mean volume of transfusion being $17.9 \pm$ $13.7 \mathrm{ml}$.

The total transfusion requirements of the infants who had received preoperative indomethacin were compared with the requirements of those who had not received the drug. The mean transfusion in the group treated with indomethacin was $23.2 \pm 13.1 \mathrm{ml}(\mathrm{n}-11)$ and in the group without indomethacin $15.1 \pm 18.1 \mathrm{ml}(\mathrm{n}-50)$.

One infant who had indomethacin before operation developed pulmonary bleeding during operation. The tracheal tube was changed twice during the operation. The bleeding was felt to be secondary either to overly vigorous ventilation or to mechanical trauma to the left lung from retraction. This infant had poor pulmonary function for approximately 24 hours; however, the bleeding subsided shortly after operation. The patient subsequently did quite well.

Temperatures recorded in the intensive care unit before and after operation were compared. Some infants did suffer significant heat loss despite efforts to preserve their normal temperature. A number of them, however, were returned to the unit with temperatures higher than those recorded preoperatively. The mean temperature change was $-1.6 \pm 1.9^{\circ} \mathrm{F}$. The temperature change of each infant was compared by standard regression analysis to the infant's weight and to the duration of anaesthesia. No correlation was found to exist between the temperature change and the weight of the patient or duration of anaesthesia (correlation coefficients less than 0.12 ).

Pneumothorax was the most common postoperative complication, occuring in 23 per cent of the patients.

The mean duration of postoperative ventilatory support was 28.1 days with a range of three hours to five months. 
TABLE 11

Anaesthetic Agents ( $\mathrm{N}=63$ Patients)

\begin{tabular}{|c|c|c|c|c|c|c|c|}
\hline & $\mathrm{O}_{2}$ & $\mathrm{~N}_{2} \mathrm{O}$ & Halothane & Ketamine & Pancuronium & d-tubocurare & Succinylcholine \\
\hline $\begin{array}{l}\text { Number of Patienls } \\
\text { Mean dose }\end{array}$ & $\begin{array}{c}63 \\
49.6 \%\end{array}$ & $\begin{array}{c}61 \\
50.4 \%\end{array}$ & $\begin{array}{l}2 \\
0.5 \%\end{array}$ & $\frac{1}{2 \mathrm{mg} \cdot \mathrm{kg}^{-1}}$ & $1.2 \pm 0.07 \mathrm{mg} \cdot \mathrm{kg}^{-1}$ & $0.67 \pm 0.31 \mathrm{mg} \cdot \mathrm{kg}^{-1}$ & $7.8 \pm 4.23 \mathrm{mgg} \cdot \mathrm{kg}^{-1}$ \\
\hline
\end{tabular}

The mean hospital stay of the patients who remained at Children's Hospital was $74 \pm 53$ days.

The mortality was related to the degree of preoperative respiratory distress. Fifty-five patients were available for follow-up. One patient died within 72 hours of operation. This patient was noted above as arriving at the operating room with an isoproterenol infusion. Six infants died within 30 days and four died after 30 days. When mortality was compared to preoperative respiratory distress, Group A (severe respiratory distress syndrome) and Group B (mild to moderate respiratory distress syndrome) had mortality rates of 24 per cent and 8 per cent respectively. Two of the Group A deaths occurred approximately five months postoperatively. The most common causes of death were necrotizing enterocolitis, intracranial haemorrhage or progressive bronchopulmonary dysplasia.

\section{Discussion}

The incidence of patent ductus arteriosus in the general population has been estimated to be from 0.02 to 0.04 per cent. ${ }^{5.6}$ The frequency in the preterm infant is uncertain, but it is considerably higher than in term infants with appropriate birth weights. Kitterman ${ }^{7}$ found the incidence to be 15.3 per cent in 111 preterm infants with birth weights less than 1750 grams. Siassi $i^{3}$ found the incidence to be 21 per cent in 150 infants weighing less than 2500 grams. The incidence is inversely related to increasing birth weight and gestational age.

The communicable disease center has reported the incidence of patent ductus arteriosus to have more than doubled during the last decade. This may be an actual increase or it may reflect an improvement in diagnosis or survival rate for small preterm infants. ${ }^{1}$

The anaesthetic management of critically ill preterm infants undergoing ligation of patent ductus arteriosus has not been widely discussed. The one report published in the anaesthesiology literature ${ }^{8}$ states that no anaesthesia was used, nor is any necessary.
The notion that preterm infants are insensitive to pain has not been proven. Anyone who has tried to start an intravenous in one of these babies can attest to the fact that they withdraw their extremities and that there is inevitably a rise in pulse rate and blood pressure. It has been our experience that nitrous oxide will attenuate this response and is not associated with any significant haemodynamic change.

In reports where the anaesthesia is mentioned the trend has been to paralyze the infant and to supplement with local anaesthesia or nitrous oxide. ${ }^{9-14}$ As explained above, the choice of relaxant was dependant upon the infant's respiratory status before operation. The dosages in Table II are total doses. These relaxants were administered slowly to avoid any significant haemodynamic changes. Potent inhalational anaesthetics such as halothane and ethrane were avoided due to their narrow limits of safety in this patient population.

The metabolic and cardiorespiratory problems associated with hypothermia in preterm infants have been well described. ${ }^{15}$ Extreme care must be taken to maintain the temperature within a normal range. The data in this report indicate that neither the size of the infant nor the duration of anaesthesia is related statistically to the change in body temperature. If the operating room environment is properly modified, as described above, then minimal temperature fluctuations may be expected.

The number of infants who were treated preoperatively with indomethacin is too small for statistical analysis. These infants, however, appear to be unusually prone to renal failure, which is a reported toxic effect of this drug. ${ }^{16}$ This must be taken into account when administering drugs excreted by the kidney. Infants who received indomethacin also appeared to require more blood in the operative period.

It has been suggested " that the neonatal intensive care unit is a more suitable location to perform these operations. It is argued that the heat loss is less and that the risk of infection is decreased. In our experience heat loss can be kept at a minimum and the infection rate following 
TABLE III

Hospital Survival Following Ligation of Patent Ductus Arteriosus in Preterm Infants

\begin{tabular}{lccc}
\hline \multicolumn{1}{c}{ Author } & $\begin{array}{c}\text { Number } \\
\text { of } \\
\text { Patients }\end{array}$ & $\begin{array}{c}\text { Number of } \\
\text { Intraoperative } \\
\text { Deaths }\end{array}$ & $\begin{array}{c}\text { Percent } \\
\text { Survival }\end{array}$ \\
\hline Oxnard (11) & 21 & 0 & 86 \\
Lippman (8) & 24 & 0 & 62 \\
Williams (13) & 20 & 0 & 55 \\
Kitterman (7) & 10 & 0 & 80 \\
Clarke (17) & 22 & 0 & 77 \\
Levitsky (14) & 29 & 0 & 69 \\
Nelson (20) & 32 & 0 & 59 \\
Coran (12) & 30 & 0 & 77 \\
Thibeault (21) & 21 & 0 & 62 \\
Kilman (9) & 12 & 0 & 75 \\
Murphy (10) & 11 & 1 & 54 \\
Lewis (22) & 10 & 0 & 80 \\
Gay (18) & 45 & 0 & 67 \\
Cupta (23) & 4 & 0 & 75 \\
Merritt (2) & 24 & 0 & 79 \\
Neuman & 55 & 0 & 80 \\
$\quad$ Total & 385 & 1 & 71 \\
\hline
\end{tabular}

surgery in the operating room has not been a problem. The decreased risk of contamination and easy accessability to surgical instruments and blood bank facilities reinforce the position that ligation of patent ductus arteriosus can be done safely and effectively in the operating room suite.

Table III summarizes the survival statistics from a number of authors. In the patients reported here there were no deaths during operation. Table III shows that out of 370 patients reported in the literature, there was only one death during operation; this occurred during the induction of anaesthesia.

The overall survival rate of the 55 infants who were available for follow up was 80 per cent. This compares favorably with the survival rates in earlier reports and with the survival rate for all preterm infants with respiratory distress syndrome (approximately 80 per cent). When the survival rates for the infants were compared by weight (see Table I) no significant difference was found between groups. There was, however, a significant difference in survival between infants with severe respiratory distress syndrome and those classified as mild to moderate. This has also been shown in previous reports. ${ }^{7.13,17-19}$

\section{REFERENCES}

1. Krovetz, L.J. \& Kattwinkel, J. Commentary on Patent Ductus Arteriosus Complicating the Re- spiratory Distress Syndrome. Journal of Pediatrics 90: 262-263 (1977).

2. Merritt, T.A., DiSessa. T.G., Feldman, B.H., KirkPatrick, S.E., Gluck. L. \& Friedman, W.F. Closure of the Patent Ductus Arteriosus with Ligation and Indomethacin: A Consecutive Experience: Journal of Pediatrics 93: 639-646 (1978).

3 Siassi, B., Blanco. C., Cabal, L.A. \& Coran, A.G. Incidence and Clinical Features of Patent Ductus Arteriosus in Low-Birthweight Infants: A Prospective Analysis of 150 Consecutive Born Infants. Pediatrics 57: 347-351 (1976)

4. Langman, J. Medical Embryology. Williams and Wilkins Company, Baltimore, p. 81 (1969.

5. Gardiner, J.H. \& Keith, J.D. Prevalence of Heart Discase in Toronto Children: 1948-49 Cardiac Registry. Pediatrics 7: 713-721 (1951).

6. ANDERSON, R.C. Causative Factors Underlying Congenital Heart Malformations, I: Patent Ductus Arteriosus. Pediatrics 14: 143 (1954).

7. Kitterman, J.A., Edmunds, H.F., Gregory, G.A. Heymann, M.A., Tooley, W.H. \& Rudol.ph, A.M. Patent Ductus Arteriosus in Premature Infants. New England Journal of Medicine. 287: 473-477 (1972).

8. Lippmann, M., Nelson, R.J., Emmanouilides, G.C., Diskin, J. \& THibeault, D.W. Ligation of Patent Ductus Arteriosus in Premature Infants. British Journal of Anaesthesia. 48: 365-369 (1976).

9. Kilman, J.W., Kakos. G.S., Williams, T.E., Craenen, J. \& Hosier, D.M.: Ligation of Patent Ductus Arteriosus for Persistent Respiratory Distress Syndrome in Premature Infants. Journal of Pediatric Surgery, 9: 277-281 (1974).

10. Murphy, D.A., Outerbridge, E., Stern, L., Karn, G.M., Jegier, W. \& Rosales, J. Management of Premature Infants with Patent Ductus Arteriosus. Journal of Thoracic and Cardiovascular Surgery. 67: 221-228 (1974)

11. Oxnard, S.C., McGough, E.C., Jung, A.L. \& Ruttenderg, H.D. Ligation of the Patent Ductus Arteriosus in the Newborn Intensive Care Unit. The Annals of Thoracic Surgery. 23: 564-567 (1977).

12. Coran, A.G Cabal L Slassi, B \& Rosenkrantz, J.G. Surgical Closure of Patent Duetus Arteriosus in the Premature Infant with Respiratory Distress. Journal of Pediatric Surgery. 10: 399-404 (1975).

13. Williams, W.H., M.D., Gelband, H., Bancalari, Bauer, C., Garcia, O., Tamer, D. \& Kalser, G.A. The Ductus Debate: Ligation in Prematurity. Annals of Thoracic Surgery. 22: $151-156(1976)$.

14. Levitsky, S., Fisher, E., Vidyasagar, D., HasTREITER, A.R., BenNeTt, E.J., Raju, Y.N.K. \& ROPER, K. Interruption of Patent Ductus Arteriosus in Premature Infants with Respiratory Distress Syndrome. Annals of Thoracic Surgery. 22: $131-136$ (1976).

15. Adamsons. K. \& Towell, M.E. Therma Homeostasis in the Fetus and Newborn. Anesthesiology 26: 531-548(1965).

16. Winther, J., Prinz, M., Mendoza, S., Kirkpat. RICK, S. \& FRIEDMAN, W. The Influence of Indomethacin on Neonatal Renal Function. Pediatric Research. 11:402 (1977). 
17. Clarke, D.R., Paton, B.C., Way, G.L. \& StEWART, J.R. Patent Ductus Arteriosus Ligation and Respiratory Distress Syncrome in Premature Infants. Annals of Thoracic Surgery. 22: 138-145 (1976).

18. Gay, J.H., Dalley, W.J.R., MEyer, B.H.P., Trump, D.S., Cloud, D.T. \& Molthan, M.E. Ligation of the Patent Ductus Arteriosus in Premature Infants: Report of 45 Cases. Journal of Pediatric Surgery. 8: 677-683 (1973).

19. LeEs, M.H. Commentary: Patent Ductus Arteriosus in Premature Infants - A diagnostic and Therapeutic Dilemma. Journal of Pediatrics. 86: 132-134 (1975).

20. Nelson, R.J., Thibeault, D.W.. EmmanouILIDES, G.C. \& LIPPMAN, M. Improving the
Results of Ligation of Patent Ductus Arteriosus in Small Preterm Infants. Journal of Thoracic and Cardiovascular Surgery. 71: 169-177 (1976).

21. Thibeault, D.W., Nelson, R.J., Rosengart, R. \& OH, W. Patent Ductus Arteriosus Complicating the Respiratory Distress Syndrome in Preterm Infants. Journal of Pediatrics. 86: 120-126 (1975).

22. Lewis, C.E., JR., Coen, R.W., Talbot, W. \& EDWARDS. W.S. Early Surgical Intervention in Premature Infants with Respiratory Distress and Patent Ductus Arteriosus. The American Journal of Surgery. 128: 829-834 (1974).

23. Gupta, J.M,, van Vliet, P.K.J., Fisk, G.C. \& WRIGTH, J.S. Ductus Ligation in Respiratory Distress Syndrome. Journal of Thoracic and Cardiovascular Surgery. 63: 642-647 (1972).

\section{RÉSUMÉ}

Les auteurs ont fait la revue des dossiers de 70 bébés prématurés présentant un syndrome de détresse respiratoire associé la plupart du temps à une insuffisance cardiaque rebelle, et qui ont subi une ligature de canal artériel. Ils décrivent l'approche péri-opératoire de ces cas. Comme anesthésique, on a utilisé le mélange protoxyde d'azote-oxygène et un relaxant musculaire. Tous les bébés ont été ventilés manuellement à l'aide d'un système de Jackson Rees humidifié. Toutes les interventions ont été effectuées en salle d'opération. On n'a relevé aucun décès per-opératoire. Une attention toute spéciale a été apportée au maintien de la température des enfants à l'aide de diverses méthodes décrites dans le texte. Le taux global de survie de 80 pour cent se compare favorablement aux taux de survie rapportés chez les prématurés présentant un syndrome d'insuffisance respiratoire. L'approche et les méthodes utilisées dans ces cas sont considérées satisfaisantes par les anesthésistes et les chirurgiens. 